\title{
Performance measurement of the after-sales service network: Evidence from the automotive industry
}

\author{
Shahnoush Shahrouzi Fard* and Seyed Mehdi Hosseini
}

Department of Management, Firouzkoh Branch, Islamic Azad University, Firouzkoh, Iran

\begin{tabular}{l}
\hline C H R O N I C L E \\
\hline Article history: \\
Received March 25, 2015 \\
Received in revised format \\
August 62015 \\
Accepted August 92015 \\
Available online \\
August 102015 \\
\hline Keywords: \\
After-sales services \\
Quality of services \\
Customer satisfaction
\end{tabular}

\section{Introduction}

The after-sales activities are recognized as a primary source of revenue, profit and competitive advantage for all industries (Cohen \& Lee, 1990; Lele, 1997; Flynn, 1997; Seth et al., 2005). Top and middle management, therefore, have to concentrate on the definition of a structured firm performance measurement system for the after-sales services (Hayes \& Dredge, 1998; Neuhaus, 1997; Kotler \& Armstrong, 2010). Besides, since many parameters are engaged in the after-sales service supply chain, a comprehensive and multi-attribute set of measures requires to be considered consistently at each level of the supply chain. However, small attention has been given by scientific and managerial literature to this topic. Gaiardelli et al. (2007) were some of the pioneers who tried to fill this gap, presented an integrated framework for the after-sales network performance measurement, and studied two automotive case firms and their official service networks. The cases indicated that performance

\footnotetext{
* Corresponding author. Tel: +98912-2030413

E-mail address: nonoush@yahoo.com (S. Shahrouzi Fard) 
measurement systems of various supply chain actors ought to be aligned to reach strategic consistency. More specifically, the performance of various factors at the process level of the framework concurred in detecting the after-sales service overall performance towards the final customer. Moreover, linkages at other levels may be required in ensuring consistency between strategic and operational objectives, inside the firms as well as for the whole supply chain. Saccani et al. (2006) analyzed the role of aftersales services in manufacturing contexts, and the related after-sales performance measurement systems. The role attributed to after-sales activities in the information technology and consumer electronics and household appliance industries indicated an orientation to contribute company image, customer satisfaction and retention.

Saccani et al. (2007) investigated the configuration of the after-sales supply chain by analyzing three issues: The degree of vertical integration, the degree of centralization, and the decoupling of activities. They reported that configuration choices change, implying that no "one best way" existed. In addition, many companies developed multiple configurations. Choices were affected by drivers, including the attractiveness of the after-sales business, the strategic priorities, the characteristics of the physical good and the services offered, and the configuration of the manufacturing and distribution supply chain. Ehinlanwo and Zairi (1996) performed a study on the concept of car after-sales service as implemented in Germany and it was performed by benchmarking four key players including Fiat AG, Nissan Deutchland, Toyota GmbH, and Ford Werk AG. They explained the necessary factors responsible for the contributing on the after-sales sector in automobile marketing.

Chitcharoen et al. (2013) studied different relationships among brand awareness, channel, perceived web quality, and perceived quality towards after-sales service of the all-in-one office products' firm in Bangkok, Thailand. They reported a decline on the sales of some single-function products when a multifunction product was opened. They reported that only channel, perceived web quality, and perceived quality were positively associated with after-sale service of the company.

According to Dombrowski and Engel (2014), the automotive market is presently under remarkable change. Currently, a transformation is under away from the conventional internal combustion based engines, to electric mobility. It is now unclear, which technology within the individual mobility will become dominant. However, that the change of mobility will have strong influence on the entire supply chain. Dombrowski and Engel (2014) concentrated primarily on problems in the primary commodity sector such as the development of electric vehicles, the technological core problems or the infrastructure. Nevertheless, the effects on the indirect fields and specifically the highly profitable automotive aftermarket are to the most extent remain unnoticed. In this area, there is a lag of funded reviews and scientific methods on how to handle technology shortages and its effects. All the various Stakeholders operating in the field of the automotive aftermarket will be influenced by this change. However, in particular for small and medium-sized car repair shops it is not straightforward to create new innovative and extensive strategies next to their day-to-day business. Dombrowski and Engel (2014) developed a method, which could help the stakeholders of the automotive aftermarket understand their existing strategy and detect alternative strategies to modify their existing strategy.

Kurata and Nam (2013) investigated the impact of uncertainty on after-sales service decisions by comparing different information structures in a two-stage supply chain. The model showed that uncertainty may temporally reduce the discrepancy between customers' optimal service level and a company's service decisions according to profit maximization. Nevertheless, uncertainty will never contribute on supply chain performance. They detected whether such accidental outperformance could mislead the company into making erroneous after-sales service decisions due to misunderstandings regarding uncertainty. Moreover, they showed that a firm's effort to provide efficient service operations could improve the likelihood of accidental outperformance. 
According to Kim et al. (2007), performance-based contracting is changing service support supply chains in several industries such as aerospace and defense. Known as "power by the hour" in the private sector and as "performance-based logistics" (PBL) in defense contracting, Kim et al. (2007) planned to replace traditionally implemented fixed-price and cost-plus contracts to contribute product availability and reduce the cost of ownership by tying a supplier's compensation to the output value of the product created by the customer (buyer). They introduced a multi-task principal-agent model to support resource allocation and implemented it to investigate commonly observed contracts. In their model the customer encountered a product availability requirement for the "uptime" of the end product.

Lele (1997) developed an after-sales service model, which investigated the costs customers absorb when their facilities fails. He presented a framework to identify the most cost-effective service strategies for various customer segments, and detected how these strategies could influence equipment design. They recommended that the framework could also be implemented to forecast how product and service strategies ought to change in response to new technologies and evolving customer requirements.

Kasper and Lemmink (1989) concentrated on the perceived quality of after sales services for a case study on a large supplier of office e equipment active in the Dutch market. In this study, the perceptions of the industrial customer on after sales services were then compared with the view the service managers in the company had about these customer perceptions. Van Birgelen et al. (2002) studied the interaction between perceived service performance and national cultural characteristics in the formation of customer satisfaction for three forms of after-sales service contact facilities. They reported that, in contrast to the traditional face-to-face service encounter, the perceived quality-satisfaction relationship was specifically moderated by national culture in the case of an after-sales service contact mode mediated by technology. Cavalieri et al. (2007) provided a comprehensive review of the existing body of knowledge about after-sales performance measurement systems. They also presented an integrated framework for after-sales performance measurement consisting of business, process, activity, and development and innovation and provided an empirical application of the framework to four case studies in durable consumer products; automotive, home appliances and consumer electronics.

Anderson et al. (1994) explained how expectations, quality, and price could influence on customer satisfaction and why customer satisfaction, in turn, ought to influence on profitability. Their findings supported a positive effect of quality on customer satisfaction, and, in turn, profitability. They explained the economic advantages of increasing customer satisfaction and discussed why increasing market share actually could lead to lower customer satisfaction.

Lovelock (1983) concentrated on specific categories of services and presented five schemes for classifying services in ways that transcend narrow industry boundaries. Zeithaml et al. (1988) determined an exhaustive set of factors potentially influencing the magnitude and direction of four gaps on the marketer's side of their service quality model. Majority of factors involved communication and control processes used in service companies to manage employees. They also include consequences of these processes, such as role clarity and role conflict of contact personnel.

\section{The proposed study}

This paper presents an empirical investigation to determine important factors influencing on customer satisfaction in after-sales service network in automotive industry. The study designs two questionnaires, one for measuring the quality of after-sales services and the other for measuring customers' satisfaction based on Parasuraman's work (Parasuraman et al., 1985). The sample size is calculated as follows, 


$$
n=\frac{N \times z_{\alpha / 2}^{2} \times p \times q}{\varepsilon^{2} \times(N-1)+z_{\alpha / 2}^{2} \times p \times q},
$$

where $N$ is the population size, $p=1-q$ represents the yes/no categories, $z_{\alpha / 2}$ is CDF of normal distribution and finally $\varepsilon$ is the error term. Since we have $p=0.5, z_{\alpha / 2}=1.96$ and $N=850$, the number of sample size is calculated as $n=265$. The study selects a sample of 265 randomly selected customers out of 850 people who received the services from an automotive firm in Iran. Cronbach alpha has calculated as 0.82 , which is well above the minimum desirable level. In terms of personal characteristics, 188 (73\%) of the participants were male and 78 (27\%) ones were female. Fig. 1 shows other personal characteristics of the participants.

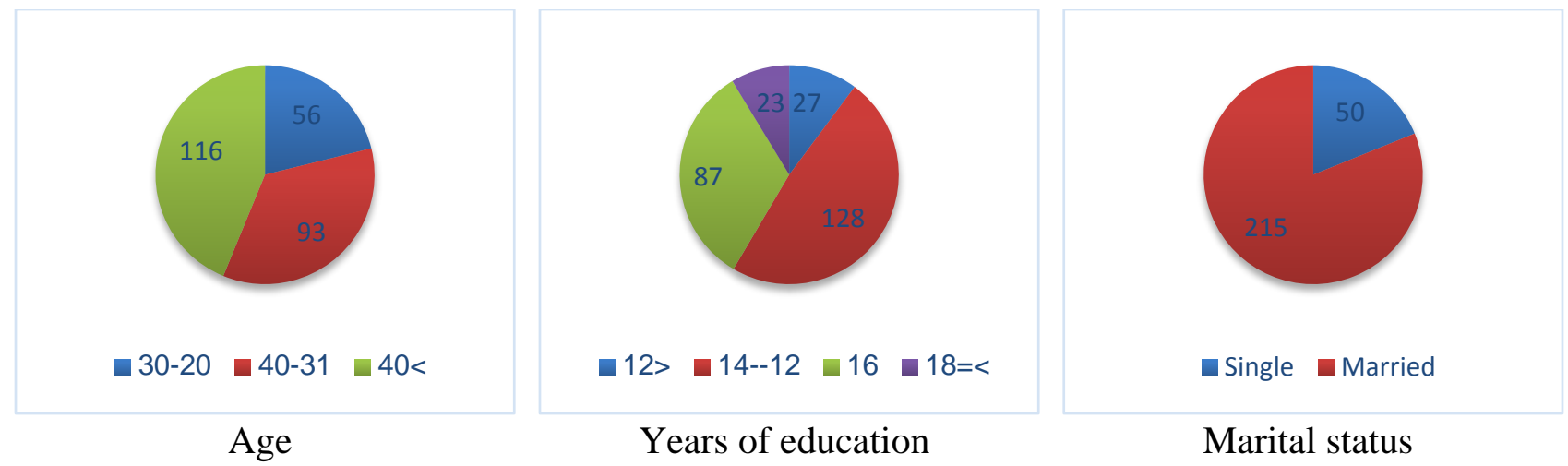

Fig. 1. Personal characteristics of the participants

As we can observe from the results of Fig. 1, most participants were middle aged people who had some university educations and mostly married. Kolmogorov-Smirnov has indicated that the data were not normally distributed so we may use Spearman correlation to examine different hypotheses of the survey as follows,

1. There is a relationship between quality of services and customer satisfaction.

2. There is a relationship between being responsiveness and customer satisfaction.

3. There is a relationship between speed of services and customer satisfaction.

4. There is a relationship between cost of services and customer satisfaction.

5. There is a relationship between quality of after-sales services and customer satisfaction.

\section{Results, discussion and conclusion}

Using Spearman correlation the study has detected a positive and meaningful relationship between services and customer satisfaction ( $\mathrm{r}=0.48$, Sig. $=0.01$ ), a positive relationship between being responsiveness and customer satisfaction $(\mathrm{r}=0.51$, Sig. $=0.01)$ and finally a positive relationship between speed of operation customer satisfaction $(\mathrm{r}=0.45$, Sig. $=0.01)$. Moreover, there was a positive and meaningful relationship between cost of services and customer satisfaction $(\mathrm{r}=0.68$, Sig. $=0.01)$, and a positive relationship between quality of services of after-sales services and customer satisfaction $(r=0.61$, Sig. $=0.01)$. The results of this survey are somehow consistent with other similar studies presented in the literature such as Ehinlanwo et al. (1996) and Gaiardelli et al. (2007). Most previous studies have emphasized on relative importance of after-sales services on customer satisfaction and our findings are also in line with previous studies. 


\section{Acknowledgement}

The authors would like to thank the anonymous referees for constructive comments on earlier version of this paper.

\section{References}

Anderson, E. W., Fornell, C., \& Lehmann, D. R. (1994). Customer satisfaction, market share, and profitability: Findings from Sweden. The Journal of Marketing, 58(3), 53-66.

Van Birgelen, M., de Ruyter, K., de Jong, A., \& Wetzels, M. (2002). Customer evaluations of aftersales service contact modes: An empirical analysis of national culture's consequences. International Journal of Research in Marketing, 19(1), 43-64.

Cavalieri, S., Gaiardelli, P., \& Ierace, S. (2007). Aligning strategic profiles with operational metrics in after-sales service. International Journal of Productivity and Performance Management, 56(5/6), 436-455.

Cohen, M. A., \& Lee, H. L. (1990). Out of touch with customer needs? Spare parts and after sales service. MIT Sloan Management Review, 31(2), 55.

Chitcharoen, C., Kanthawongs, P., Wathanasuksiri, K., \& Kanthawongs, P. (2013). A model to investigate the influence of channel, perceived web quality, brand awareness, perceived quality on after-sales service of the all-in-one office products. Procedia-Social and Behavioral Sciences, 88, 8-12.

Dombrowski, U., \& Engel, C. (2014). Impact of Electric Mobility on the after Sales Service in the Automotive Industry. Procedia CIRP, 16, 152-157.

Ehinlanwo, O. O., \& Zairi, M. (1996). Best practice in the car after-sales service: An empirical study of Ford, Toyota, Nissan and Fiat in Germany-Part 1. Business Process Management Journal, 2(2), 39-56.

Flynn, J. (1997). The odyssey of a customer inquiry. Management Review,86(5), 62.

Gaiardelli, P., Saccani, N., \& Songini, L. (2007). Performance measurement of the after-sales service network-Evidence from the automotive industry. Computers in Industry, 58(7), 698-708.

Hayes, J., \& Dredge, F. (1998). Managing customer service. Gower Publishing, Ltd.

Kasper, H., \& Lemmink, J. (1989). After sales service quality: views between industrial customers and service managers. Industrial Marketing Management,18(3), 199-208.

Kim, S. H., Cohen, M. A., \& Netessine, S. (2007). Performance contracting in after-sales service supply chains. Management Science, 53(12), 1843-1858.

Kotler, P., \& Armstrong, G. (2010). Principles of marketing. Pearson Education.

Kurata, H., \& Nam, S. H. (2013). After-sales service competition in a supply chain: Does uncertainty affect the conflict between profit maximization and customer satisfaction?. International journal of production economics, 144(1), 268-280.

Lele, M. M. (1997). After-sales service-necessary evil or strategic opportunity?.Managing Service Quality: An International Journal, 7(3), 141-145.

Lovelock, C. H. (1983). Classifying services to gain strategic marketing insights. The Journal of Marketing, 47(3), 9-20.

Neuhaus, C. A. (1997). Flexible forecasts: a key to better customer service. Hospital Materiel Management Quarterly, 18(4), 61-66.

Parasuraman, A., Zeithaml, V. A., \& Berry, L. L. (1985). A conceptual model of service quality and its implications for future research. The Journal of Marketing, 49(4), 41-50.

Saccani, N., Songini, L., \& Gaiardelli, P. (2006). The role and performance measurement of after-sales in the durable consumer goods industries: an empirical study. International Journal of Productivity and Performance Management, 55(3/4), 259-283.

Saccani, N., Johansson, P., \& Perona, M. (2007). Configuring the after-sales service supply chain: A multiple case study. International Journal of Production Economics, 110(1), 52-69. 
Seth, N., Deshmukh, S. G., \& Vrat, P. (2005). Service quality models: a review. International Journal of Quality \& Reliability Management, 22(9), 913-949.

Zeithaml, V. A., Berry, L. L., \& Parasuraman, A. (1988). Communication and control processes in the delivery of service quality. The Journal of Marketing, 52(2), 35-48. 